\title{
PRÁCTICAS DISCURSIVAS E IDENTIDADES DE GÉNERO DE LAS MUJERES AYMARAS DEL NORTE CHILENO (1980-2015)
}

\author{
DISCURSIVE PRACTICES AND GENDER IDENTITIES OF THE AYMARA \\ WOMEN OF NORTHERN CHILE (1980-2015)
}

\author{
Vivian Gavilán Vega* y Ana María Carrasco*
}

\begin{abstract}
Presentamos resultados de investigación acerca de los discursos que elaboran las dirigentas de organizaciones de mujeres que se adscriben al pueblo aymara en el norte de Chile entre 1980 y 2015 y que van configurando procesos de afirmación de identidades de género. El análisis de entrevistas aplicadas y declaraciones realizadas por ellas a lo largo de este período da cuenta de prácticas discursivas que van modificándose de acuerdo con los contextos sociopolíticos y según las dinámicas de participación política que ellas mismas lideran. Se pueden identificar tres momentos: el primero expone la demanda por el reconocimiento de la diferencia cultural en el contexto de la sociedad nacional; el segundo se caracteriza por el énfasis en las demandas ciudadanas; y el tercero por considerar la dominación masculina en los contextos de colonización. Este recorrido muestra procesos de afirmación de identidades de género que se van configurando en la lucha política por un nuevo tipo de inclusión en la sociedad nacional. Los discursos elaborados van mediando las representaciones de género y produciendo nuevas subjetividades y por tanto constituyen herramientas para la lucha en contra de las estructuras de dominación.
\end{abstract}

Palabras claves: identidades, género, etnicidades, aymara.

We present research results on the speeches made by the leaders of women's organizations that belong to the Aymara people in northern Chile between 1980 and 2015 and that are configuring processes of affirmation of gender identities. The analysis of applied interviews and statements made by them during this period gives account of discursive practices that are modified according to the sociopolitical contexts and according to the dynamics of political participation that they themselves lead. Three moments can be identified: the first exposes the demand for the recognition of the cultural difference in the context of the national society; The second is characterized by the emphasis on citizen demands; And the third to consider male domination in colonization contexts. This tour shows processes of affirmation of gender identities that are configured in the political struggle for a new type of inclusion in the national society. The discourses elaborated mediated the representations of gender and produced new subjectivities and therefore constitute tools for the struggle against structures of domination

Key words: identities, gender, ethnicities, aymara.

\section{Introducción}

Los procesos de afirmación de las identidades de género de las mujeres indígenas de América Latina ha sido un tema de interés para investigadores ocupados en el estudio de la participación política de los pueblos originarios (Wilson, 1988, Curiel 2002, Hernández 2007, CEPAL 2013, Sckmunck 2013, Sciortino 2015). Estos trabajos han consignado la importancia de los contextos sociohistóricos para la comprensión de los procesos identitarios, mismos que se expresan en prácticas discursivas que nos permiten conocer a un nuevo sujeto social y político de los Estados-naciones de la región. En esta línea, presentamos reflexiones respecto del proceso de elaboración de las identidades de género que han ido construyendo las mujeres aymaras del norte chileno desde la década de los ochenta del siglo pasado hasta las primeras décadas de este siglo. Se trata de describir e interpretar la visión que tienen estas de las relaciones de género en su colectividad. Siguiendo a A. Hernández (2007), buscamos conocer las distintas maneras en que las mujeres aymaras imaginan y reflexionan respecto de sus identidades de género y conciben sus estrategias de lucha en contra de la discriminación étnica, racial y de género.

Entendemos el concepto de identidades de género como procesos de interiorización de las tradiciones culturales que configuran las prácticas sociales de mujeres y hombres. Se trata de "la cristalización al interior de un individuo de las relaciones sociales y culturales basadas en las diferencias que distinguen los sexos y que definen, particularmente,

* Universidad de Tarapacá, Departamento de Antropología. Arica, Chile. Correo electrónico: vtgavilanv@uta.cl; acarrasco@uta.cl 
relaciones significantes de poder; en el seno de las cuales él/ella está comprometido/a y a las cuales es inducido/a a reproducir o a rechazar" (basado en Godelier, 2010:25 y Scott 1996). En tanto prácticas históricas, las identidades individuales son a la vez una y múltiple por el número de relaciones que mantenemos con los otros (Godelier 2010) y se constituyen en el juego de la autoafirmación y asignación identitaria, entre "autoidentidad" y "exoidentidad" (Cuche, 1996: 88-89).

El discurso como práctica social incluye ideas y sentidos que tienen para los actores sus comportamientos; es decir, las interpretaciones que hacen de sí mismos y de su entorno. Hace referencia a sistemas de representación que regulan lo que se puede hacer con el lenguaje en una situación y un contexto determinados (Foucault 1970). Podemos afirmar que las relaciones de género son mediadas por la actividad de representación del discurso que va configurando las identidades sociales de mujeres y de hombres según sus contextos socioculturales y sociopolíticos.

Desde esta perspectiva, abordamos el material discursivo producido por las mujeres para conocer su percepción acerca de su condición de género. Sistematizamos 17 narrativas provenientes de entrevistas aplicadas a mujeres dirigentas cuyas edades van de los 35 a los 60 años, de escolaridad básica, media y universitaria, residentes en las zonas rural y urbana de las actuales regiones Arica-Parinacota y Tarapacá. Además, reunimos material documental producido por las líderes en los momentos señalados. Complementariamente se utiliza material etnográfico recogido en reuniones y acciones colectivas de las agrupaciones de mujeres residentes en la ciudad y en la zona rural y que se desplegaron no solo en el norte, sino también en la capital, i.e. en Santiago de Chile.

El corte temporal escogido se debe a la emergencia de la comunidad aymara ante la sociedad nacional y al Estado-nación chilenos. Las primeras organizaciones que reivindicaron derechos a la diferencia cultural datan de la década de los ochenta del siglo pasado. Un grupo de estudiantes universitarios convocaron a la colectividad aymara de la ciudad de Arica para agruparse con la finalidad de denunciar la discriminación negativa de sus tradiciones culturales y la racialización que imponía el proyecto colonial moderno. Cercanos al movimiento indígena que se despliega en Bolivia, se plantearon una lucha política de resistencia basada en acciones dirigidas al reconocimiento del pueblo aymara. Para ello la literatura indigenista constituyó un referente importante para reflexionar respecto de su pasado, presente y futuro en el contexto de los Estados-naciones modernos. A partir de este momento el movimiento indígena en el norte del país comienza a cuestionar al Estado monocultural y a demandar nuevas formas de ciudadanía.

A lo largo de los casi cuarenta años que considera el período investigado, las mujeres aymaras han participado en este proceso de lucha social y política. ¿Cómo se han configurado las identidades de género en esta trayectoria? Es la pregunta que intentamos responder siguiendo la evolución de sus prácticas discursivas.

El primer apartado del artículo expone los discursos medulares de la primera fase, el que se caracterizó por la afirmación de la diferencia cultural de los aymaras y las demandas por el reconocimiento como pueblo. El segundo segmento del trabajo muestra el momento en el que las dirigentas aymaras van abriendo espacios para la reflexión acerca de ciudadanía y especifican demandas sociales. El tercer y último ítem avanza hacia las dos últimas décadas en las que aspectos tales como los problemas de dominación masculina son enfrentados en la complejidad de la sociedad nacional y los procesos de globalización. Tratándose de una comunidad heterogénea social, económica y culturalmente, los discursos son también heterogéneos y diversos. Las entrevistas analizadas no da cuenta de esta diversidad. Es evidente que el material empírico presenta limitaciones; sin embargo, debido a que nuestro interés es avanzar hacia el conocimiento y comprensión de las formas de participación política de las mujeres aymaras y, en particular, de la visión que ellas han ido construyendo sobre sí mismas como colectivo que forman parte de las estructuras de dominación, optamos por un punto de partida para ir profundizando por etapas. Este punto de partida aborda la heterogeneidad distinguiendo los materiales discursivos de mujeres con mayor escolaridad y residentes en la ciudad y de los discursos de dirigentas con menor escolaridad y más cercanas al trabajo campesino.

\section{La Emergencia del Pueblo Aymara en el Norte Chileno}

La afirmación de la diferencia cultural constituye la principal bandera de lucha para demandar 
procesos de inclusión social y política en el Estado y la sociedad nacional como pueblos originarios. Como señalan Wilson (1988) Sckmunck (2013) y Sciortino (2015), las mujeres han ido participando del movimiento social impulsado por los pueblos originarios y por el de mujeres que reivindican mayor equidad de género. En el norte chileno fueron hombres y mujeres aymaras que en la segunda mitad de los ochenta del siglo pasado comienzan a reivindicar derechos culturales al Estado nacional. Las acciones colectivas se sumaron al proceso de lucha en contra la dictadura militar y en menor medida al movimiento de mujeres que se había desplegado a nivel nacional. En la primera parte de los noventa y en el contexto del proceso participativo que se generó por la nueva ley indígena se visibiliza a la mujer aymara. Las líderes buscan especificar las relaciones de género en su colectividad ${ }^{1}$. Enfatizaron en las diferencias con la comunidad que no se adscribía a los pueblos originarios del norte chileno y que, según su convicción, seguían principios culturales occidentales. La valoración del pasado indígena permitió reaccionar a la histórica discriminación étnica, y apropiándose de los estudios antropológicos indigenistas que hablaron de complementariedad entre los géneros como principio básico de la filosofía andina ${ }^{2}$, propusieron por primera vez su propia concepción acerca de las relaciones sociales de género. Elaboran un contradiscurso para romper con el estigma. Los contenidos manifiestos en este evidencian una búsqueda por principios filosóficos "propiamente andinos" que habrían sostenido las sociedades no colonizadas en el pasado. Distingue tres dimensiones para comprender la posición y condición de mujeres y hombres: la cosmovisión, la pareja en el matrimonio y la postura de género "auténticamente andina". El concepto aymara pacha (universo: tiempo-espacio) se entiende como "orden armónico de todos los elementos del universo organizado simbólicamente en masculino y femenino, con cualidades opuestas pero que se complementan formando la unidad, cuya dinámica está dada por su carácter recíproco". El concepto jaquichasiña o unión de la pareja conyugal, contiene la idea de que "el hombre y la mujer son parcialidades heterogéneas que se complementan logrando una unidad de la familia" (Flores, 1996: 4). Esta dirigenta agrega que la unidad está constituida por dos individuos distintos diametralmente opuestos y que esta diferencia permite el equilibrio en la unidad familiar. Se trata de una relación complementaria. Plantea que el concepto chacha-warmi (relación esposoesposa) es el que constituye el eje de la postura andina de género, porque se basa en la práctica ancestral de convivencia entre mujeres y hombres andinos, constituyendo un modelo alternativo de género que la sociedad occidental puede adoptar.

De este modo, por primera vez un grupo de mujeres aymaras exponen ante la comunidad regional una historia de las relaciones de género y una propuesta que reivindica la diferencia cultural. $\mathrm{La}$ interpretación del pasado es una estrategia para una crítica del presente y una puerta que abre un nuevo camino en el contexto de dominación cultural. No obstante, al mismo tiempo, las bases de la diferencia cultural afirmada en un pasado esencial y ahistórico las lleva a invisibilizar las desigualdades sociales basadas en los regímenes de género dominantes e impuesto por el Estado moderno y colonizador. Si bien importa marcar la diferencia para apelar al reconocimiento cultural de la colectividad que se identifica como aymara, las asimetrías de género al interior de la misma se invisibilizan. El concepto chacha-warmi sostiene la ideología de la complementariedad. Ideología, ya que las ideas respecto de las diferencias sociales entre mujeres y hombres conducen a mantener el poder de género y el statu quo de las relaciones familiares; cuestión que será retomada por las líderes del siglo XXI. Estas observaciones no deben minimizar la importancia que tuvo este discurso contrahegemónico, pues produjo un referente para la afirmación positiva de la identidad aymara que impulsó a acciones colectivas orientadas a cuestionar las relaciones de poder presentes en las tradiciones culturales de género hegémonicas que privilegia a Occidente.

Los dirigentes y las dirigentas con menor escolaridad y con mayor apego al trabajo campesino iniciaron un proceso más lento de reacción a la exoidentidad estigmatizante, por medio de procesos de valoración de la lengua y de su pasado. Acompañada-os por organizaciones no gubernamentales regionales y nacionales las agrupaciones de mujeres reflexionaron respecto de su posición mediante su participación en diversos eventos con otras colectividades indígenas y no indígenas. Se vieron a sí mismas valoradas externamente por su trabajo, por sus voluntades para generar organizaciones locales que les permitieron plantear problemas contingentes. Al compartir sus experiencias de vida y conocer las de otras mujeres fueron generando reflexiones en torno a sus aspiraciones 
y a afirmar su identidad de género a partir de la valoración de la importancia de su trabajo para la reproducción familiar y comunitaria ${ }^{3}$. La alteridad, representada en las mujeres no indígenas, se basó en su ascendencia inka (entidad ancestral masculino-femenino), no como la historia oficial, sino como descendientes de antepasados locales. La distinción se sintetizaba en los términos q'araindio- $a$ que se caracterizaba por formas de vida diferentes (Gavilán 2005). En este grupo el concepto chacha-warmi no se resignificó como en el caso de las organizaciones urbanas y no se elaboró un discurso coherente respecto de la diferencia, pero se reflexionó en torno al importante rol que desempeñaban las mujeres en la reproducción del hogar y en la comunidad aymara. Por otra parte, la alteridad respecto de los hombres aymaras se elaboró con elementos de la tradición cultural de género cuyos contenidos simbólicos y sociales se entendían en el contexto del ciclo vital y de las categorías de parentesco: hija/hermana/esposa. Es decir, las posiciones de jerarquías y sus argumentos para justificarlas tenían que ver con los roles que la comunidad exige cumplir a hombres y mujeres a lo largo de la vida personal con su hogar, familia y comunidad. En este sentido, los privilegios masculinos de representatividad social y política o la ocupación de los hombres en las tareas productivas y reproductivas con mayor prestigio, o las posibilidades del ocio permitido a estos, pero menos a las mujeres, fueron pensados y reflexionados colectivamente generando cambios personales y colectivos. Un ejemplo que ilustra esta situación se puede ver en un acta (1986) del centro de madres de la estancia de Central Citani, comunidad de Isluga ubicada en el altiplano chileno. Esta indicaba que los hombres que golpearan a sus esposas durante la fiesta patronal serían sancionados por sus parientes con una multa. Esto ocurre cuando las instituciones comunales (como los padrinos de matrimonio, los caciques y los jueces de distrito) fueron reemplazadas por los juzgados de policía local. Se trató así de una iniciativa de las mujeres, apropiándose de un espacio organizativo creado por el Estado para fines personales y colectivos.

\section{Mujeres por una Mayor Participación Ciudadana}

En los últimos años de la década de los noventa el aumento de agrupaciones femeninas propició una diversidad de discursos. Las políticas estatales dirigidas a disminuir la pobreza definieron a los pueblos originarios como un grupo objetivo. Los programas sociales de afirmación positiva facilitaron la emergencia de dirigentas que adhieren parcialmente a la postura anterior. Se trató de líderes locales que plantearon los problemas concretos de las mujeres. La vinculación de las dirigentas aymaras con líderes feministas o con organizaciones nacionales de mujeres contribuyeron a nuevos debates. Entre estos destacan el reconocimiento de las jefas de hogar, mayor participación política y erradicación de la violencia de género.

Las narrativas se distancian de la antropología indigenista para situarse en las necesidades básicas, en las aspiraciones por resolver dificultades cotidianas y en redefinir su ciudadanía basada en la etnicidad. En este contexto, la pobreza debe ser superada; especialmente el estigma construido desde la exoidentidad del indio y la escasez de recursos socioeconómicos y sociopolíticos. En este sentido, la condición étnica en el espacio nacional se concibe como una oportunidad para mejorar las condiciones de vida de las mujeres y para denunciar la hegemonía masculina en el hogar y en las organizaciones sociales.

La presidenta del Consejo Nacional Aymara y miembro del Consejo de la Corporación Nacional para el Desarrollo Indígena (CONADI) plantea que "hay que aprender nuevas formas de participación para ayudar a las mujeres aymaras. Muchas de ellas no saben cómo defenderse, no saben como pedir ayuda al Estado" (I.Q. 1998). La conciencia de pertenecer a un pueblo indígena dentro del escenario nacional va acercando a las mujeres a la reflexión de su ciudadanía:

Quisiera ser Presidenta de la República. Me gustaría trabajar en la mesa de la mujer como coordinadora de las agrupaciones de mujeres. Veo con alegría que las mujeres nos estamos organizando más y que estamos apostando y dando todo de sí como persona. Realmente yo me siento más que contenta y orgullosa de pertenecer a esta agrupación y mis ambiciones quizá van más allá de ser una simple dirigente en el ámbito social porque siempre me ha gustado ayudar a las demás personas, tratar de que se superen y logren sus metas y también me gustaría poder hacerlo en un ámbito de 
poder lo que es ser alcaldesa, ser concejal o quizás llegar mucho mas allá; pero sin ser ambiciosa (I.Q. 1998).

Los discursos dejan ver que se piensan a sí mismas con necesidades de aprendizaje e información para lograr lo que se proponen. Para ello se identifican mecanismos como educacarse cívicamente, capacitarse para exponer sus problemas y mantenerse informadas. Las entrevistas son redundantes en estos temas: "las mujeres están desinformadas. No saben leer ni escribir, son tímidas, tienen miedo de hablar" ( L.M. 2000). Las mujeres tienen que tener la capacidad suficiente para decir yo quiero esto y yo quiero lo otro" (J.M. 2001).

Las líderes promueven la participación social y política en el contexto de las dinámicas regionales y nacionales:

Yo siempre les he pedido que hablen en los talleres, pa que sepan presentarse, porque es un terror que le tienen a presentarse en público, yo también le tenía en principio a pescar el micrófono... y no, yo siempre les he dicho que uno nunca tiene que venir a presentarse con voz baja ¡NO! Usted tiene que entrar de frente, con su pecho bien alto, porque usted es una persona y está solicitando algo que el Estado tiene la obligación de darle si usted lo solicita, si no lo solicitamos no nos dan ná, pero nunca ir con la cabeza baja por muy derrotada que estén... de frente, y tengo harta plata en los bolsillos aunque tenga pocos papeles, eso hay que construir, eso le falta a las mujeres $(\ldots)(\ldots)$ he crecido como mujer, he aprendido lo que antes yo no me expresaba con las autoridades, no hablaba en público,... hoy en día no, y por último digo lo que pienso y lo que siento... no me interesa que quede la grande, pero yo digo lo que yo siento y lo que pienso por lo general... no soy pa' andarle con documento, me dicen J. leéte ese documento y hablar sobre ese documento olvídense, puedo decir a lo mejor tres palabras que lo que estaba escrito, pero todo el resto es mío. Entonces me he fortalecido como mujer (J.M. consejala de la comuna de Putre, 2002).
La lucha en contra la discriminación étnica formó parte importante de las experiencias de participación social y política:

Yo participo para luchar en contra de la discriminación. O sea el que uno entre a un servicio público y te vean con pollera, $o$ con trenzas o con ojotas, inmediatamente te paran y no tienes el mismo trato. Ahora, si uno va más arregladita recién te toman en cuenta. Entonces, quebrar esos esquemas es lo que me ha llevado a estar trabajando en estos temas. Quebrar ese esquema de no como vestirte es lo que tú eres. Cambiar el esquema de que los servicios públicos estén al servicio de las personas, y no las personas al servicio de ellos. Cambiar el tema que siempre al indígena se le nombre como un "indigente" o "un pobrecito". Somos sujetos de derecho. Porque uno dice: ah, es pobre entonces es indígena. Y no, es una forma distinta de vida. Entonces, yo creo que eso me ha llevado, y bueno, obviamente luego vienen los derechos, pero fue más que nada por un tema de discriminación. Y no solamente como persona, sino también los recursos hídricos, territoriales (...) (M.G. presidenta Consejo Nacional Aymara, 2000).

Las interpretaciones que hacen las dirigentas del pasado y el análisis de la sociedad contemporánea se expresa en un discurso de afirmación de sus identidades étnicas y de género para luchar en contra de la exclusion social y política:

Yo espero que la brecha de la discriminación se acorte. Espero que las mujeres indígenas sean capaces de hacer ella la historia, no que otros vengan y le pongan la historia, si no que ellas sean capaces de decidir, de pensar. Creo que las mujeres indígenas en un futuro no muy lejano estén, quizás, en lugares más alto. No solamente lo que es la dirigencia, sino a nivel de diputados y senadores, por qué no Presidenta, Presidente. Creo que para allá vamos, y ¿Por qué para allá? Porque es la única forma de implementar políticas al alcance nuestro (M.G. (M.G Asociación de Mujeres de Arica y Parinacota. Integrante del Consejo de 
Pueblos Originarios de la Región de Arica y Parinacota, 2001).

Esta misma dirigenta comparte su interpretación respecto del pasado de las relaciones de género de la colectividad aymara en el contexto del proceso político que implicó instalar la situación y condición de mujeres y de hombres y la exigencia de presentar propuestas:

\begin{abstract}
Antiguamente nuestra cultura aymara era femenina, cuando nosotros nos unimos a los quechuas, con los incas, ellos eran de una forma machista, patriarcal, entre nosotros la mujer mandaba.., matriarcal. Entonces, cuando se unieron ambas partes se formó el chacha warmi, esto es lo que uno quiere ver en el futuro. Que la mujer no sea ni más ni menos que el hombre, pero que sean de una forma efectiva no? que sean, no tanto igual, más que puedan conjugar ambos, o sea, eso de la igualdad es como muy irreal. Porque eso no se da, ni en una pareja se da, pero sí que hombres y mujeres puedan trabajar bien y respetándose en todos los ámbitos.
\end{abstract}

Las experiencias de participación social y política son compartidas entre ellas y enuncian las dificultades que ponen sus maridos o los compañeros para la participación política.

"El hombre te hace a un lado, porque piensan que ellos solamente pueden ocupar cargos de poder o cargos altísimos, pero no miran que las mujeres somos capaces e incluso lo harían mejor que el hombre" (I.Q. presidenta del Consejo Nacional Aymara y miembro del Consejo de la Corporación Nacional para el Desarrollo Indígena (CONADI, 2000).

\section{Las Identidades de la Mujer Aymara en la Sociedad Nacional, Colonizada y Compleja}

En la primera década de este siglo se perfilan nuevos liderazgos femeninos. Las líderes que guían la participación social y política de las mujeres son diversas, representando la heterogeneidad sociopolítica y sociocultural de la colectividad a la que pertenecen. En este momento se observan los efectos que la política de afirmación positiva diseñada por el Estado, a lo largo de dos décadas, va teniendo en la comunidad indígena (ver Gavilán y Lagos 2014). Como ocurre a nivel nacional, se va produciendo la desarticulación de las redes supralocales. Tanto las organizaciones de mujeres como las agrupaciones mixtas se van reduciendo a sus espacios locales sin perder vínculos con las redes nacionales e internacionales. La influencia y el acompañamiento realizado por los organismos no gubernamentales para apoyar los procesos participativos van disminuyendo debido a la cooptación de los recursos de la cooperación internacional por parte del gobierno y al débil financiamiento del Estado para sostener programas sociales por fuera de las líneas establecidas por los gobiernos tanto de la Concertación de Partidos por la Democracia como por la Alianza por Chile ${ }^{4}$. Se trata de un período en el que emergen líderes con nuevos discursos, pero con bases de apoyo restringidas. Nuevas generaciones de jóvenes, ahora con mayor escolarización y vinculadas a redes sociales más amplias, denuncian la discriminación de las mujeres al interior de las colectividades indígenas y plantean el problema de la violencia en contra de la mujer, en forma más clara,

Las voceras del sector que podríamos llamar más radical, son mujeres profesionales con un discurso elaborado para la comunidad nacional e internacional. Estos manifiestan una búsqueda por afirmar su identidad en una sociedad colonizada y compleja. El concepto chacha-warmi como modelo de género del pasado se plantea ahora como un proyecto, una utopía y se observan esfuerzos por comprender a la sociedad aymara como una colectividad heterogénea. Cuestionan las relaciones de poder existentes que vulneran los derechos humanos de los pueblos originarios y al mismo tiempo el de las mujeres y ensayan estrategias para el cambio. Estas líderes se declaran feministas y participan de distintos movimientos políticos. Revisamos aquí tres tipos de argumentos, los que coinciden solo en partes. El discurso enunciado por la más joven pone atención en cuatro aspectos: reconocimiento de la diferencia cultural, violencia y derechos sexuales y reproductivos, el modelo chacha warmi como horizonte utópico, y el rechazo a las políticas estatales acerca de equidad de género. En este contexto, la alteridad con las mujeres no indígenas se elabora sobre la base de las prácticas cotidianas de vida: 
"yo veo que somos diferentes, partiendo por la cosmovisión (...) lo que vas comiendo todos los días; aunque tú vivas en la ciudad (...) vas en eso. Sabes que eres diferente al resto no?, que tú comes diferente, que hablas diferente (...) que tienes una manera de pensar diferente (...) que el tema de la religión es diferente, que el tema de la afectividad es diferente ...".

Siendo diferentes de las mujeres que no siguen las tradiciones culturales indígenas, se consideran parte de la comunidad política nacional. En este sentido, reconocen la hegemonía de género que despliegan las instituciones estatales y las Iglesias al conjunto de las mujeres y hombres:

En nuestro país no solo se violan solamente los derechos de las mujeres indígenas si no todo el tema de los derechos de las mujeres. Siendo que somos un país laico, que la Iglesia por ejemplo se interponga en las decisiones políticas del país, en el tema de la píldora del día después, en el tema de los anticonceptivos, en el tema de aborto, no aborto, me entiendes?, esos son temas de derechos sexuales y reproductivos. Sobre la sexualidad no es fácil hablar. Tú llegas a un taller y te das cuenta que jamás las personas, las mujeres han sabido qué es un orgasmo, entonces tú te das cuenta que falta entender que no por ser un pueblo indígena vas a ser sesgado de, no se po` de sexualidad. Bueno, nosotros no tenemos tantos problemas como tienen otras culturas que entregan a las niñas a hombres adultos, no tenemos esos problemas; pero sí hay muchos problemas... que mira yo te lo planteo como una inquietud, no te lo aseguro pero a mí por ejemplo y en eso quiero hacer una investigación en el tema del incesto $(\mathrm{H}$. H. presidenta de la Coordinadora de la Mujer Indígena Rural y Urbana de la región Arica Parinacota y vocera del Consejo Autónomo aimara, sin pertenencia a partido político, 2010).

Su perspectiva crítica hacia la idealización de la comunidad aymara contemporánea la lleva a revisar las posturas basadas en la dualidad y equilibrio:
Somos una cultura machista. El chacha warmi son utopías que hoy no se practican que sí se practicaron, que son parte de nuestra cosmovisión; pero el tema de la dualidad para mí es una utopía. Por ejemplo cuando yo planteo eso delante de los hombres poco más que me comen, porque el tema de idealizar mi cultura no puedo ser así, dentro de la cultura suele ocurrir eso, que uno idealiza su cultura o por ejemplo yo en estudios que he hecho he puesto el tema de la violencia hacia la mujer indígena que es más alta, es mucho más alta y las denuncias son mucho más altas que cómo se te ocurre, y es la realidad o sea es la realidad, es parte de una investigación de casi un año que hicimos, porque la mujer indígena está inserta dentro del sistema patriarcal, que permite en mínima medida su participación y visibilización pública (H.H. presidenta de la Coordinadora de la Mujer Indígena Rural y Urbana de la región Arica Parinacota y vocera del Consejo Autónomo aimara, sin pertenencia a partido político, 2010).

Estas declaraciones han generado conflictos entre los y las líderes del movimiento indígena, ya que su unidad se basa en las diferencias con la sociedad no indígena y porque en su interior no hay una sola postura frente al tema. Pero dar visibilidad a los problemas que enfrentan las mujeres constituye el propósito de estos nuevos liderazgos.

Otro de los aspectos presentes en este contradiscurso dice relación con las críticas hacia las políticas de género por parte del gobierno:

Le pedí a la CONADI las políticas de género y se pasaron como dos o tres meses y vuelvo a insistir y me llaman por teléfono para indicarme que ellos no tienen, que se la pasaron al PRODEMU entonces que ellos no ven ese tema (...) o sea te das cuenta que el organismo más importante en la temática indígena no tiene la cuestión de género (H.H. presidenta de la Coordinadora de la Mujer Indígena Rural y Urbana de la región Arica Parinacota y vocera del Consejo Autónomo aimara, sin pertenencia a partido político, 2010). 
Otra visión respecto de la situación actual de las mujeres aymara en este período la observamos en las declaraciones realizadas en otra dirigenta. Plantea que el sistema patriarcal como contexto es clave para comprender la situación de la mujer aymara. Para ella existirían dos formas de participación social en las que se desenvuelven: a) como ciudadanas sin reconocimiento étnico, y b) como mujeres que se identifican como aymaras y reivindican derechos a la diferencia cultural:

\begin{abstract}
Desde la mirada de la cultura occidental se las ve participativas de los procesos que esta le ofrece a través de políticas públicas que buscan su integración definitiva al Estado nacional. Decimos definitiva, porque ya debieron vivir como pueblo el proceso de chilenización con la imposición cultural principalmente a través de las escuelas, posteriormente la evangelización del territorio, y sumados a ellos los tiempos del salitre donde se hicieron parte de la economía imperante. Hoy, la integración es más sutil, ya no es imposición, sino convencimiento. Así, las mujeres aymara se han organizado como mujeres jefas de hogar, mujeres emprendedoras, mujeres productoras. Al hacerlo, si bien reivindican sus derechos como sujetas, dejan de lado la visión comunitaria (A. F., dirigenta de un partido político de centroizquierda, 2008).
\end{abstract}

Lo comunitario es lo que identifica a la colectividad indígena. Es en la comunidad local donde las mujeres debieran reflexionar acerca de los problemas que las aquejan y respecto de los cambios que desean impulsar. Especialmente "los embates de la globalización y los flagelos de la modernidad que pueden ser dañinos como la pérdida del idioma o las aguas".

En este discurso se explicitan los problemas de inequidad que comparten con las mujeres no indígenas, como

Violencia intrafamiliar, exclusión de los espacios de poder, dificultades para participar social y políticamente, triple jornada de trabajo y en la mayor parte de los casos están supeditadas al ambiente privado de la familia y el hogar. Es decir, están afectas también a patrones de raigambre patriarcal, pero a ello debemos sumarle las diferencias culturales. Y deberán ser ellas y (ellos) quienes busquen y definan el camino adecuado para no desaparecer tras la rápida integración a la cultura dominante (A. F., presidenta de la Coordinadora de la Mujer Indígena Rural y Urbana de la región Arica Parinacota y vocera del Consejo Autónomo aimara, sin pertenencia a partido político, 2010) $)^{5}$.

El modelo chacha warmi es revisado sin perder de vista las particularidades de las relaciones de género entre los aymaras. La alteridad está nuevamente basada en el pasado indígena que configuró la idea de lo "comunitario". Esto le permite definir la estrategia de participación colectiva y la reivindicación de la unidad política del pueblo.

El tercer discurso identificado presente en este período lo expone la presidenta del Consejo Nacional Aymara de Mallkus y Tallas ${ }^{6}$. En este se identifican aspectos transversales de la situación de las mujeres indígenas a nivel nacional. Uno de ellos, plantea que estas

Aun no han abordado en profundidad el trabajo específico que tiene que ver con género, visibilidad, especificidad, igualdad de oportunidades, empoderamiento, etc., conceptos que no conocen bien, y por tanto no los manejan (C.F., 2011).

Afirma que las mujeres indígenas estarían insertas en la lucha social de sus comunidades, eclipsando sus demandas específicas. En este sentido se construye la identidad por lo que le falta para ser ciudadana, según los términos técnicos del diseño de políticas públicas. Pero reconoce los avances visibles de la participación de las mujeres aymaras:

La participación de la mujer aymara ha cambiado notablemente, siempre tuvo un rol más de transmisión cultural, de crianza, de trabajo familiar, pero desde hace algún tiempo ha incursionado en lo dirigencial y eso ha sido un gran paso. La mujer aymara hoy está desarrollando un liderazgo, se ha empoderado y hoy podemos ver a mujeres dirigentes de organizaciones, e incluso en comunidades. También en este ámbito tenemos algunas mujeres aymaras concejales, 
pero es un campo muy difícil de abarcar por el sistema de 25 elecciones que tenemos en nuestro país, sin duda un espacio que debemos conquistar (C.F. 2011).

La dirigente se pregunta “¿En qué estamos las mujeres aymaras hoy? A lo que responde lo siguiente:

Estamos ahora trabajando y tratando de fortalecer la participación de la mujer en distintas instancias. Estamos preocupadas de ser aporte de cuidar nuestros territorios, de mantener nuestra cultura, de que se respeten nuestros derechos y sobre todo de que la política pública sea acorde a los estándares internacionales a los cuales nuestro país se ha suscrito. Estamos luchando por construir un mejor futuro para las nuevas generaciones y que las propuestas de las organizaciones sean la base de una política pública acorde con nuestra cosmovisión (C.F.2011).

\section{Reflexiones Finales}

Hemos intentado rescatar las trayectorias desplegadas por las mujeres aymaras del norte de Chile a partir del momento en que comienza la lucha de los pueblos originarios de esta parte del territorio nacional; esto es, en la década de los 80 del siglo pasado. Con el seguimiento de los discursos de dirigentas que lideraron y que lideran hoy los procesos reivindicativos de los derechos de las mujeres en los últimos treinta años, se proponen interpretaciones respecto de la visión que tienen de las relaciones de género en la sociedad y cultura aymara contemporáneas.
La pregunta ¿cómo se han configurado las identidades de género en esta trayectoria? nos llevó por el recorrido de una lucha política en la que las mujeres se ven como un actor reflexivo compartiendo espacios de poder complejos.

El estudio de las narrativas de sus experiencias como dirigentas pone de relieve discursos contrahegemónicos que se van desarrollando según los contextos sociopolíticos que se desplegaron en la etapa final de la dictadura y en la fase postdictadura. Hemos consignado que en el período elegido se pueden identificar tres tipos de discursos, mismos que si bien no son adoptados por el conjunto de las organizaciones, van presentando los cambios que se despliegan. En tanto forman parte de procesos, evidencian momentos diferenciados que van evolucionando de acuerdo con las dinámicas de apropiación que hacen las líderes de ideas y prácticas de su entorno.

Todos los discursos visualizados en este trabajo dan cuenta de un proceso de afirmación de las identidades étnicas y de género como un problema fundamentalmente político. La reflexividad de las dirigentas muestra un camino hacia el cuestionamiento de las relaciones de poder en el que se desenvuelven su vida cotidiana. De aquí que sus prácticas discursivas se inscriban en una búsqueda por denunciar las múltiples aristas que las estructuras de dominación imponen a sus vidas.

\section{Agradecimientos}

Este trabajo forma parte del proyecto FONDECYT No 1140022 titulado Tradiciones Culturales de Género y Etnicidad en la Colectividad Aymara del Norte Chileno.

Agradecemos las evaluaciones recibidas, mismas que contribuyeron a mejorar el trabajo escrito.

\section{Referencias Citadas}

Albó, X. y Mamani, M.

1980 Esposos, suegros y padrinos entre los aymaras. En, Parentesco y Matrimonio en los Andes, Universidad Católica del Perú, Lima, Perú.

Bourque, S. y Barren, K.

1976 Campesinas y comuneras: subordinación en la Sierra Peruana. Estudios Andinos Año 5, Volumen I No 1 1976, Pittsburg. U.S.A.

Burkett, E.

1976 La mujer durante la conquista y la primera época colonial. Estudios Andinos Año 5, Volumen I No 11976 , Pittsburgh. U.S.A
Carrasco, A. M.

1993 Mujeres y participación social en la sociedad aymara contemporánea. En, Huellas, Centro de Estudios para el Desarrollo de la Mujer. 1993 Santiago, Chile.

Comisión Mujer, Mesa Regional Indígena de Santiago. 2012 Memoria Seminario Internacional "Mujeres Indígenas: su Aporte y Liderazgo en los distintos Procesos Sociales Indígenas. Editores Emilio José Jiménez Cáceres, Loreto González Corante.

ht tp://www.conadi.gob.cl/documentos/ SeminarioInternacionaldeMujeres2011.pdf 
Curiel, Oshi, C.

2002 Identidades esencialistas o construcción de identidades políticas? El dilema de las feministas negras. Otras Miradas n 296113.

Cuche, D.

2004 La noción de cultura. Nueva Visión Buenos Aires Argentina

De la Cadena, $\mathrm{M}$.

1985 La comunera como productora. Allpanchis $\mathrm{N}^{\circ} 25 \mathrm{XV}$ vol. XXI 1985, Cusco, Perú.

Flores, I. y Flores, E.

1997 Seminario Desarrollo y Mujer Rural. Ponencia presentadaen Las Dinámicas de la Participación Social y Política de las Mujeres. Tercer Congreso Nacional Mujer y Desarrollo Local. Arica, octubre.

Faucoult, M.

1970 La arqueología del saber. Siglo XX Editores, México.

Gavilán, V.

2005 Vivian Gavilán; Identidades Sociales a Inicios del Siglo XXI; p. 77-102; España; 2005; Revista de Dialectología y Tradiciones Populares; Num.2; Fasc.; Vol. LX.

Gavilán, V y Lagos, F.

2014 Integración social y subordinación política de los aymara. Un estudio de la certificación estatal indígena en el norte chileno. Estudios Atacameños, 49: 95-110.

Godelier, M.

2010 Comunidad, sociedad, cultura. Tres claves para comprender las identidades en conflicto. Cuadernos de Antropología Social, 32: 13-29. (C) FFyL-UBA-ISSN 0327-3776.

Harris, O.

1985 Una Visión Andina del Hombre y la Mujer. En Allpanchis, № 25, XV, Vol. XXI 1985, Cusco-Perú.

Harris, $\mathrm{O}$.

1988 La Pachamama: Significados de la Madre en el discurso Boliviano. En, Mujeres Latinoamericanas, Diez Ensayos y una Historia Colectiva. Ediciones Flora Tristán Lima Perú.

Hernández, R.A.

2007 Entre el etnocentrismo feminista y el esencialismo étnico. Las mujeres indígenas y sus demandas de género. Debate Feminista, 24: 206-229.

Isbell, B.J.

1975 La Otra Mitad Esencial. Un Estudio de Complementariedad Sexual en los Andes. En Estudios Andinos, año V No 11975 , Pittsburg U.S.A

La Piedra, A.

1985 Roles y Valores de la Mujer Andina en Allpanchis, Nº 25, XV Vol. XXI 1985, Cusco, Perú.
Pizarro, L.

1988 Algunas Reflexiones Acerca de los Espacios Femeninos y Masculinos en las Comunidades Aymara del Sector de Isluga. Doc. de Trabajo N.10 1988, Taller de Estudios Regionales, Iquique, Chile.

Platt, T.

1980 Espejos y Maíz. El Concepto de Yanantin entre los Macha de Bolivia. En, Parentesco y Matrimonio en los Andes. E. Mayer y R. Bolton. Editores 1980,. Universidad Católica del Perú, Lima.

Rostoroswski, M.

1988 La Mujer en la Epoca Prehispánica. Doc. de Trabajo N.17 1988, Instituto de Estudios Peruanos, Lima, Perú.

Informe Sistematización IV Congreso nacional Aymara realizado bajo el proyecto Fortalecimiento de la gestión social de las organizaciones indígenas de las provincias de Arica y Parinacota, 2002. Ayni Consultores.

Sckmunck, R. A.

2013 Mujeres Mapuche: Signos de identidad [en línea]. III Jornadas del Centro Interdisciplinario de Investigaciones en Género, 25, 26 y 27 de septiembre de 2013, La Plata, Argentina. Desde Cecilia Grierson hasta los debates actuales. En Memoria Académica. Disponible en: http:// www.memoria.fahce.unlp.edu.ar/trab_eventos/ev.3414/ ev.3414.pdf

Sciortino, $\mathrm{S}$

2015 Procesos de organización política de las mujeres indígenas en el movimiento amplio de mujeres en Argentina. Consideraciones sobre el feminismo desde la perspectiva indígena Universitas Humanística, 79: 65-87. http://www. redalyc.org/pdf/791/79132009004.pdf

Scott, J.

1996 El género: una categoría útil para el análisis histórico. En, Lamas, M. (1996). El género. La construcción cultural de la diferencia Sexual. PUEG y Edit Porrúa México 265-362.

Silverblatt I.

1990 Luna, Sol y Brujas. Género y Clases Prehispánicas y Coloniales. Centro de Estudios Bartolomé de la Casas e I. Silverlatt 1990, Cusco, Perú.

Wilson, F

1988 La Representación del Género en el Pensamiento Indigenista Actual. En, Mujeres Latinoamericanas Diez Ensayos y una Historia Colectiva. Flora Tristan 1988, Lima-Perú.

\section{Notas}

1 En el contexto del Seminario Internacional "Mujer Sociedad y Cambio: Sigamos Avanzando", organizado por la Municipalidad de Arica en marzo de 1996, las líderes presentaron el primer documento acerca de las relaciones de género en la comunidad aymara.

2 cf. Albo, X. y M, Mamani 1980, Bourque y Barren 1976, Burquett 1976, De La Cadena 1985, Harris, Olivia 1985, 1988, Isbell 1975, La Piedra, Aurora 1985, , Pizarro, Lucila 1988, Rostorowski 1988, Silverblatt 1990, Platt, Tristan 1980, Wilson 1988, Carrasco, A. M. 1993).

3 Durante las décadas de los ochenta y noventa se realizaron varios encuentros regionales y nacionales de mujeres indígenas y campesinas y se crearon organizaciones supralocales con el propósito de dar visibilidad a la mujer aymara a nivel nacional y generar redes de apoyo en pro de la defensa de los derechos humanos de la mujer indígena. Las autoras participaron en la mayoría de estos eventos, como profesionales del Taller de Estudios Andinos, ONG regional que cumplió una importante labor de acompañamiento en la lucha por el reconocimiento del Pueblo Aymara.

$4 \quad$ El primero reúne a partidos de centroizquierda y el segundo a los de la derecha política.

5 Flores, Alejandra http://www.observatoriogeneroyliderazgo. cl/index.php/las-noticias/3315-mujeres-aymaras hoy

6 Informe del Seminario Internacional "Mujeres Indígenas: Su Aporte y Liderazgo en los distintos Procesos Sociales Indígenas. Santiago de Chile, septiembre 2011. 